\title{
Research and Practice on the Task-Driven Teaching Mode of Computer Basic Course in Vocational Education
}

\author{
Yanming Yang \\ Qingdao Campus \\ Naval Aviation University \\ Qingdao 266041, China \\ yymqd@126.com
}

\begin{abstract}
Task-driven" is a teaching model based on the constructivist teaching theory, which embodies the teaching concept which is guided by teaching and subjected to learning. Teaching content is contained in tasks. Students actively construct concepts, principles and methods through problem solving. This paper discusses the basic connotation and advantages of "task-driven" teaching mode, analyzes the process of implementing "task-driven" teaching mode of computer basic course in vocational education, and the key of "task-driven" teaching mode. Finally, the practical effect of "task-driven" teaching of the computer basic course in vocational education is analyzed in detail. Practice has proved that this teaching mode has achieved significant improvement in classroom teaching efficiency, student learning enthusiasm and learning effect due to its clear objectives and strong operability.
\end{abstract}

Keywords - Vocational education; Teaching mode; Task-driven; Computer basic course

\section{INTRODUCTION}

The "task-driven" teaching mode is that teachers design and propose "tasks" according to students' "job tasks" and teaching topics, and give presentations, explanations and other means in the multimedia network room to provide ideas, methods, operations and Results, and then guide students learn while practicing, and complete the corresponding learning tasks [1-2]. Its distinctive feature is to improve student service skills as the goal, "position"-oriented, "task" as the main line to the computer network teaching environment as a platform, with teachers as the mainstay, students as the main body. A new teaching mode, task, teacher and student, which are formed by organically unifying many kinds of teaching methods such as inquiry, question, heuristic and practical operation, are the elements of this teaching mode [3-4].

"Task" refers to a problem from the actual job position and authenticity. The design of "task case" is the core of the teaching model. Teachers' teaching content will be hidden in one or several representative tasks in the case, in order to complete the task case as the center of teaching activities; students in the teacher's help, guidance, by the analysis of the case discussion and complete the task to obtain knowledge and skills, forming ability [5].

\author{
\[ \text { Yanmin Li } \]
English Teaching and Research Section
iddle School Jinxiang County Shandong Province \\ Yanmin Li
English Teaching and Research Section
iddle School Jinxiang County Shandong Province \\ Yanmin Li
English Teaching and Research Section
Yucai Middle School Jinxiang County Shandong Province \\ Jinxiang 272200, China \\ jxxzyzzyh@163.com
}

\section{THE ADVANTAGES OF "TASK-DRIVEN" TEACHING MODE IN VOCATIONAL EDUCATION}

\section{A. It is Beneficial to the Combination of Teaching and Guidance to Give Full Play to the Main Role of the Students}

The "task-driven" teaching mode implements the concept of "teaching as the leading role and learning as the main body", focusing on the teaching interaction and establishing a good, harmonious and harmonious teacher-student relationship. To change the one-way transfer, inheritance learning for equal exchange, teaching interaction, the student's dominant position can be fully reflected in order to devote great enthusiasm to creative learning activities. Teachers work with students to explore and share acquired knowledge and experience in participating teaching activities [6].

\section{B. It is Beneficial to Teach Students in Accordance with Their Aptitudes So as to Realize "Individualized, Hierarchical Teaching"}

Due to the different training levels and types of vocational education, multiple training objects of the same level and multiple training objects of the same type have formed diversified learning starting points and learning styles; the educational level, individuality and interests of the trainees are different; Trainees learn different lengths of time, etc. In the face of such a big difference, the use of traditional teaching methods is often ineffective. "Task-driven" teaching can be designed to the same teaching objectives at different levels of tasks to adapt to different levels of students, so that all students have a harvest, have a sense of achievement, truly personalized.

\section{It is Beneficial to Cultivate Students' Ability toAsk Questions, to Analyze and Solve Problems}

In the "task-driven" approach, students must learn to spot problems, conceive various solutions that may be addressed, and explore the best solutions to get the job done [7]. The way of thinking of recognizing problems in teaching can make students not only draw the conclusion from them, but also get enlightenment on the methods of recognizing, discovering and 
exploring problems, educating by methodology and reaching the knowledge of both The true meaning, but also freely applied purpose.

\section{It is Beneficial to Cultivate Students' Ability of Practice and Innovation}

The core of vocational education is to cultivate students' practice and innovation ability. In the "task-driven" model, task design is open on the one hand, leaving ample room for students to accomplish their tasks while also providing students with innovative opportunities. On the other hand, there are a variety of ways to accomplish the task. It can promote the divergence of thinking, train students to adopt a multi-angle and multi-modal thinking method, encourage students to complete their tasks in different ways, and improve students' ability to innovate.

\section{IMPLEMENTATION PROCESS OF "TASK-DRIVEN" TEACHING MODEL}

According to teaching practice, the implementation of "task-driven" teaching mode has four main steps: creating situations, proposing tasks; analyzing tasks and demonstrating operations; exploring and completing tasks; evaluating tasks and summarizing. The implementation process is shown in Fig.1.

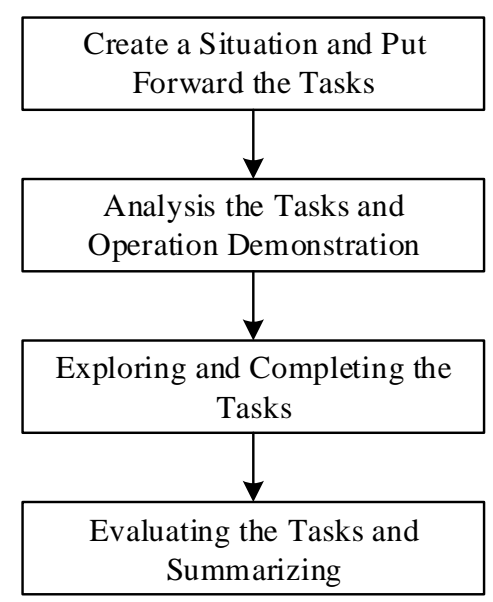

Fig. 1. The implementation process of "task-driven" teaching mode

\section{A. Create a Situation and Put Forward the Tasks}

We carefully design the teaching situation, create a teaching environment that stimulates students to explore new knowledge, and skillfully display the tasks to students. In vocational education, on the one hand, it is necessary to give full play to the function of computer simulation technology and to establish a virtual on-site environment for curriculum teaching so as to create a practical environment similar to that of military units so that students can practice training in a real audiovisual and psychological environment Adapt to the job needs of specialized personnel. On the other hand, it is necessary to make full use of practical cases to inspire learners to use their own knowledge to think about tasks, analyze and strengthen perceptual knowledge of actual job problems, and improve their ability to analyze and solve problems.

\section{B. Analysis of the Tasks and Operation Demonstration}

After the teacher put forward the task, through analyzing and guiding students to form the correct way to solve the problem, combined with the operation of the task demonstration gives the general method or concrete steps. At this time, the teacher is at the center and plays a leading role. In this process, if the teacher encounters a complicated task, the teacher can be divided into several parts, the task can be divided into several sub-tasks to complete, and the students can also explore and complete the task themselves Method of task.

\section{Exploring and Completing Tasks}

In accordance with the teacher's explanation of the task, when the church let students practice in time, while learning to do, teachers should promptly answer questions raised by students to help students complete their tasks. In this process, we advocate the use of self-exploration, collaborative learning, etc. to complete the task. According to the degree of mastery of students and the ease of teaching tasks are different, teachers can take the following ways: First, teachers demonstrate the methods and specific steps to complete the task of teaching, and then by the students to imitate the practice; Second, teachers give specific topics And the key points to complete the task, by the students on the completion of the corresponding tasks; Third, comprehensive tasks, teachers only request, by the students on the completion of the corresponding tasks. In the process of completing the task, students are in a dominant position. They not only allow students to experience the cognitive process, stimulate their interest in learning and enjoy learning, but also help students develop their ability to solve practical problems and innovations.

\section{Evaluating and Summarizing}

This is a key process. Teachers according to teaching tasks and students to complete the task situation, summed up the law and methods, the practice rose to the theoretical height, and the necessary knowledge to expand, and further enlighten ideas, broaden their horizons. Teachers check the completion of the task of students to see if they meet the requirements and make relevant records. After checking, teachers also need to make timely feedback and summary of the students to complete the task. In conclusion, we must highlight the key points of completing the teaching task, point out the existing problems and areas for improvement, find out and tap the outstanding performance of each student, and make a fair assessment and recognition, meanwhile, display the students' works or the results of the task timely, So that every student can enjoy a successful experience. Completing the task is not the ultimate goal of teaching. Rather, it aims to equip students with the new knowledge and skills to accomplish their task of self-learning and collaborative learning. Therefore, the evaluation should not only focus on the learning outcomes, but also on the learning process. It includes not only the final completion of the students, but also the students' autonomous learning and collaboration skills, interactive atmosphere and efficiency, learning attitudes and motivation, learning Methods and means, strategies and ideas to solve problems and many other aspects. 


\section{THE KeY OF "TASK-DRIVEN" TEACHING ModE}

\section{A. Determine the Design Principles of the Task Case}

The core of "task-driven" teaching mode is the design of tasks and the design of tasks, which will directly affect the success of teaching practice. In the design of mission cases, we must first grasp the design principles.

1) The principle of post: The design of the task case must be close to the actual student positions to meet job requirements. This is also the core of vocational education transformation. Such as "aircraft life information worksheet", "aircraft basic maintenance of multimedia courseware production", "aircraft fault information and statistical charts", "aircraft information management database", "airborne equipment information management" and other mission cases are source In the actual job. This principle has been used throughout the classroom teaching, teaching material preparation, laboratory construction and other work.

2) The principle of practice: Task cases must have strong operability, in order to improve students' computer operation and application ability. At the same time to consider the size of the task, the difficulty, the content of knowledge points, before and after the contact, the ability of students and many other factors. Attention should be paid to the distribution of key points and difficulties. In general, knowledge points involved in closed task cases should not be overdone, especially the key points and difficulties should be properly arranged. Too much will make it more difficult for students to study and combat the enthusiasm of some students , But open mission requirements can be higher.

3) The principle of hierarchy: In view of the uneven base of students, we should conduct teaching in different levels. When designing mission cases, it is necessary to meet the needs of most students in accordance with the requirements of the curriculum standards as well as students with better fundamentals, design enhanced task cases for them and teach them in accordance with their aptitudes.

\section{B. Building a Good Network Teaching Environment}

1) To build a network teaching environment based on the discipline teaching website: In order to ensure the smooth implementation of the "task-driven" teaching model, we put the course arrangement in computer network, and based on the campus network and computer science website, construct the network teaching environment, not only every teacher has established a personal teaching website, and provide students with personal space, to facilitate the preservation of class work. The lessons outside classroom, to the extension of the network, set up a modern educational technology for network teaching environment to support the three-dimensional, multi-level.

2) To strengthen the information construction of teaching resources and to promote the integration of teaching methods and means: In order to ensure the network teaching environment with adequate teaching resources in recent years, we have developed the multimedia courseware, network course and virtual test system, multi media courseware covers the professional occupation education teaching case more than 200, and a large number of teaching materials and auxiliary supporting learning, form the network multimedia teaching materials, teaching materials, teaching case the subject, website, website of integrated series, multi-level education training system to promote the integration of teaching resources, teaching methods and teaching means and innovation.

\section{PRACTICAL EFFECTIVENESS ANALYSis}

In the past few years, the "task-driven" teaching mode has been popularized and applied in all computer basic courses in various fields of vocational education including "Computer Information Technology", "Computer Practical Technology "," Multimedia Technology and Applications "and other courses, and achieved remarkable results.

\section{A. Effectively Improve the Quality of Teaching}

The teaching mode of "task-driven, case-based teaching, coaching and combination" is suitable for the characteristics of vocational education and computer basic courses, which is in line with the actual work and enhances the purpose, pertinence and efficiency of student learning and is deeply welcomed by students. The application of this model has played a positive role in promoting the teaching quality, teaching efficiency and improving the occupational ability of trainees in computer basic courses [8].

\section{B. Explore a Set of Effective Teaching Methods and Methods}

In the process of teaching practice, we always adhere to the principle of combining theory with practice, put forward many new concepts and new theoretical research results around vocational education in theory, and have strong applicability and maneuverability in practical application. Practice has proved that this is a set of effective teaching methods and methods.

\section{Written Vocational Education Textbooks "of Task-Driven" Series}

We have written a series of more than 10 tasks-driven textbooks for vocational education computer basic courses. The compilation of textbooks adopts a "task-driven" model to break the traditional knowledge-based structure for knowledge-based writing. Each chapter has elaborately designed several tasks. Each task consists of the following sections: task description, learning points, actual operation, relevant knowledge, and expansion. It covers the various teaching links of "task-driven" teaching, embodies the process of "teaching" and "learning" of students in teaching materials, and integrates teaching, learning and doing. 


\section{CONCLUSIONS}

In short, the "mission-driven" teaching model implemented in the vocational education computer basic course is maturing. And as a breakthrough to form a set of mature teaching mode to adapt to the teaching content, teaching methods and means, teaching material system, teaching conditions, the construction of teaching staff system, vocational education institutions it has important reference and promotion value.

\section{REFERENCES}

[1] Qiu, L. I. "The Application of Task-driven Teaching Mode in Higher Vocational Modern Chinese Course." Journal of Liaoning Higher Vocational (2015).

[2] Weiling, L. U. "Application of Double Main Task-driven Teaching Mode in Vocational English Course." Journal of Changsha University (2015).
[3] Cao, Jing Mei, TIAN-jun, and X. M. University. "Based on "TaskDriven" and "Computer and Information Technology" Teaching Mode." Computer \& Information Technology (2016).

[4] Zhang, Yan Hong, et al. "Discussion on task-driven-based small class teaching mode for computer programming courses." Computer Engineering \& Science (2016).

[5] Ping, L. I. "The Teaching Study and Application Research Based on Task-driven Flipped Classroom Model-Experiment in Foundation Computing Course in University." Journal of Shaanxi Xueqian Normal University (2017)

[6] Zhang, Li Juan, et al. "Research on Task-Driven Teaching Method Casebased for Computer Major Curriculum." Computer \& Information Technology (2017).

[7] Qiao, Chengche. "Project-based task-driven teaching mode in basic computer course." International Conference on Information and Communication Technology for Education 2014:1073-1080.

[8] Liu, Yi. "Research on the Information Technology Teaching Based on the Task-driven Mode." Journal of Anhui Vocational \& Technical College (2016). 